\title{
Dietary Pattern at 18-Month Post-Diagnosis and Outcomes of Breast Cancer Among Chinese Women with Early-Stage Breast Cancer
}

\author{
Yuanyuan Lei' \\ Suzanne $\mathrm{CHo}^{2}$ \\ Carol Kwok ${ }^{3}$ \\ Ashley C Cheng ${ }^{3}$ \\ Ka Li Cheung $\mathbb{D}^{\prime}$ \\ Roselle Lee' \\ Winnie Yeo (D) ${ }^{1,4}$ \\ 'Department of Clinical Oncology, Prince \\ of Wales Hospital, the Chinese University \\ of Hong Kong, New Territories, \\ Hong Kong SAR, People's Republic of \\ China; ${ }^{2}$ Division of Epidemiology, the \\ Jockey Club School of Public Health and \\ Primary Care, the Chinese University of \\ Hong Kong, New Territories, Hong Kong \\ SAR, People's Republic of China; \\ ${ }^{3}$ Department of Clinical Oncology, \\ Princess Margaret Hospital, Hong Kong \\ SAR, People's Republic of China; \\ ${ }^{4}$ Hong Kong Cancer Institute, State Key \\ Laboratory in Oncology in South China, \\ Faculty of Medicine, the Chinese \\ University of Hong Kong, New \\ Territories, Hong Kong SAR, People's \\ Republic of China
}

Background: Evidence of the association between dietary pattern and outcomes of breast cancer was limited in Asian women, including Chinese.

Patients and Methods: A prospective cohort study was initiated among Chinese breast cancer patients to investigate lifestyle habits and outcomes of breast cancer. At each followup, validated food frequency questionnaires (FFQ) were used to assess patients' dietary intake. This study included 1226 patients with invasive early-stage breast cancer with detailed data at 18-month follow-up after cancer diagnosis. Factor analysis was used to derive dietary patterns, whereby two dietary patterns were identified. Cox proportional hazards models were used to investigate associations between dietary patterns and time to outcome, including breast cancer recurrence, overall mortality and breast cancer-specific mortality.

Results: With a median follow-up time of 54.1 months, 165 patients had breast cancer recurrence and 98 deaths occurred. Two dietary patterns were identified: "Western dietary pattern" characterized by high intake of refined grains and cakes, red and processed meat and oil; "healthy dietary pattern" characterized by high consumption of vegetables and fruits. Participants in the highest tertile of "Western dietary pattern" did not have a higher risk of breast cancer recurrence $\left(P_{\text {trend }}=0.89\right)$, overall mortality $\left(P_{\text {trend }}=0.48\right)$ and breast cancerspecific mortality $\left(P_{\text {trend }}=0.75\right)$. Similarly, a null association existed between "healthy dietary pattern" and outcomes of breast cancer.

Conclusion: Neither dietary pattern was associated with risk of breast cancer recurrence, all-causes death or death from breast cancer. Prospective follow-up is still needed to further confirm the association between specific dietary pattern and outcomes of breast cancer.

Keywords: breast cancer, dietary pattern, recurrence, mortality, Chinese women

\section{Introduction}

Worldwide, breast cancer is the most common malignancy in female. ${ }^{1}$ For breast cancer patients, anti-cancer treatment is associated with a series of immediate as well as late toxicities, which may last for years after breast cancer treatment; these include cardiovascular disease and osteoporosis. ${ }^{2}$ Moreover, breast cancer survivors were more likely to have a second primary cancer than healthy controls. ${ }^{3}$ The heightened risk of secondary primary cancer may be explained by a combination of risk factors, including lifestyle factors, environmental exposures, genetic predisposition, as well as the effects of the initial cancer treatment. ${ }^{4,5}$ Over the past 40 years, the incidence of female breast cancer in East Asia has increased rapidly, ${ }^{6}$ and the disease has become the leading
Department of Clinical Oncology, Prince of Wales Hospital, the Chinese University of Hong Kong, New Territories,

Hong Kong SAR, People's Republic of China

Tel +86-852-26322II8

Fax +86-852-26487097

Email winnieyeo@cuhk.edu.hk 
cancer among women in Hong Kong. ${ }^{7}$ Further, notable differences have been reported in age-specific incidences of breast cancer between East and West. ${ }^{8}$ The peak age of breast cancer has been reported to be much younger in East Asians than Western women. ${ }^{9}$ As the risk of cardiotoxicity increases with age, with old age per se having more comorbidities, the causes of mortality in Asian women with breast cancer may differ from their Western counterparts. ${ }^{10}$ For instance, statistical analysis has shown that the mortality trends tend to be more favorable for women aged under 50 than those who were 50 years or older in the Asia-Pacific region. ${ }^{6}$

The potential long-term anti-cancer side effects and patients' comorbid conditions underscored the importance of survivorship care for breast cancer survivors. Adopting healthy lifestyles, including healthy dietary pattern, has become an important goal in the long-term management of breast cancer survivors. As individuals take meals with a variety of foods and a combination of nutrients, dietary pattern analysis has emerged to investigate the overall dietary habits. ${ }^{11,12}$ A series of studies have investigated the association between dietary patterns and cancer risk, while meta-analyses have shown that healthy dietary pattern might be associated with a reduced risk of breast cancer. ${ }^{13-16}$ However, evidence on the association between healthy dietary pattern and breast cancer outcomes remains limited. Two studies have evaluated the dietary pattern after diagnosis and breast cancer outcome among women in the United States (US). ${ }^{17,18}$ The results showed that higher adherence to a prudent dietary pattern, characterized by higher intakes of fruits, vegetables and whole grain, was associated with a reduced risk of non-breast cancer mortality. ${ }^{17,18}$ In addition, a third study investigated the dietary pattern at pre-diagnosis and survival among post-menopausal breast cancer survivors in Germany. ${ }^{19}$ Patients with higher adherence to healthy dietary pattern, characterized by high intake of vegetables, fruits and vegetable oil, had lower total mortality. ${ }^{19}$ To date, only one study has been conducted among Chinese women to investigate the adherence to dietary recommendations and the outcomes of breast cancer. ${ }^{20}$

Based on a prospective cohort of Hong Kong women with early-stage breast cancer, this study aimed to identify the post-diagnosis dietary pattern assessed at 18-month follow-up after cancer diagnosis; thereafter, it aimed to investigate the association between specific dietary pattern and outcomes of breast cancer patients.

\section{Patients and Methods}

\section{Study Cohort}

The Hong Kong NTEC-KWC Breast Cancer Survival Study (HKNKBCSS) is a prospective cohort study among Chinese breast cancer patients. ${ }^{21-23}$ It aims to investigate the associations between lifestyle factors, especially soy isoflavone intake with breast cancer recurrence and mortality. Eligible patients were of any age distribution, had histologically confirmed invasive breast cancer with the American Joint Committee on Cancer (AJCC) stage I-III having diagnosed no more than 12 months before study entry, ${ }^{24}$ mentally stable, Chinese women, able to read Chinese, and did not have a prior history of breast or other cancers. The study was approved by the Joint CUHK-NTEC Clinical Research Ethics Committee and the KWC Research Ethics Committee of the Chinese University of Hong Kong and the Hong Kong Hospital Authority.

Participants were recruited from two regional cancer centers in Hong Kong (Prince of Wales Hospital and Princess Margaret Hospital). These two hospitals take care of about one-third of all incident breast cancer cases each year in Hong Kong. Newly diagnosed breast cancer patients who were receiving treatment in these two hospitals were screened. Between January 2011 and February 2014, 2890 Chinese women with newly diagnosed breast cancer attended new case clinics in those two hospitals. After checking the medical records, a total of 2003 women were eligible for this study. Individual potential patients were provided with an invitation letter to the study. They were then contacted by phone and were invited into the study within the next two weeks. Among all eligible subjects, 1462 cases provided written informed consent and participated in the study (response rate: 73.0\%). Among the remaining cases, 513 (25.6\%) refused to participate, $18(0.9 \%)$ could not be contacted and 10 $(0.5 \%)$ refused treatment for breast cancer.

Consented patients were interviewed at baseline, 18month, 36-month and 60-month after breast cancer diagnosis. During follow-up interviews, patients were reassessed with the same questionnaires conducted at baseline assessment. A telephone call would be made prior to the planned interview, which would coincide with their scheduled clinic follow-up.

As of January 2019, the 60-month follow-up interview had been completed. The average time between the first interview and the latest interview was 57.1 months. This study was based on the dietary data assessed at 18 -month 
follow-up (which was conducted between 12 and 24 months after breast cancer diagnosis). In total, 1310 patients completed this interview (participation rate $89.6 \%)$.

\section{Data Collection of Socio-Demographic Characteristics and Other Co-Variables}

The baseline and follow-up interviews were conducted face-to-face by trained interviewers. During each interview, validated questionnaires were used to assess dietary intake, physical activity and quality of life (QoL). Physical activity was measured by a validated modified Chinese Baecke questionnaire. ${ }^{25}$ European Organization for Research and Treatment of Cancer Core Cancer Quality of Life Questionnaire (EORTC QLQ-C30) was used to measure the QoL. Detailed methods for dietary assessments are described below. Structured questionnaires were used to obtain detailed information on sociodemographic characteristics (age, marital status, occupation, education, household income), reproductive history, menopausal status, use of alternative complementary medicine, history of benign breast disease, family history of breast cancer in first-degree relatives, active and passive smoking, alcohol use and prior medical history. Anthropometric measurements including body weight and height were measured based on standard protocol. Based on body mass index (BMI) classification of the Asia-Pacific region, patients can be categorized into 4 groups as follows: underweight $<18.5 \mathrm{~kg} / \mathrm{m}^{2}$, normal $18.5-22.9 \mathrm{~kg} / \mathrm{m}^{2}$, overweight $23-24.9 \mathrm{~kg} / \mathrm{m}^{2}$, obese $\geq 25 \mathrm{~kg} / \mathrm{m}^{2} .{ }^{26}$

\section{Dietary Intake and Dietary Pattern Assessment}

At 18-month follow-up assessment, patients were asked to report their dietary intake over the previous year. Within a face-to-face interview, a validated food frequency questionnaires (FFQ) was used to collect information on dietary intake. ${ }^{27}$ The FFQ contained 109 food items, and a commonly used portion size was specified for each food item. Patients reported the frequency of consumption and average amount of each food item. In order to help patients clearly estimate their intake, food photographs with individual food portions were provided at the interview. Total energy intake was calculated based on a reference book named Chinese Food Composition Tables. ${ }^{28}$ To reduce the complexity of dietary data, the 109 food items in the FFQ were combined into 17 groups based on the similarity of food type and nutrient profiles as well as local eating habits in Chinese population. The original absolute food intake was standardized by serving per day before performing factor analysis to avoid problems arising from different measurement units and different intake amount. Principal component and factor analysis were used to derive dietary patterns based on the daily consumption of the 17 food groups. Extraction of principal components was followed by an orthogonal transformation (Varimax rotation function) to achieve a simple structure with good interpretability. The food groups retained were based on an eigenvalue greater than 1.0, the scree plot and the interpretability of the factors.

The derived factors were labeled based on the variables of food groups with the highest factor loading as well as the interpretation of the data. ${ }^{29}$ Factor loadings represent correlation coefficients between the food groups and the dietary pattern. For each participant, dietary pattern score was calculated using the regression method, first summing intakes of all the food groups, and then weighted by factor loading. ${ }^{11}$ It represented the individual's level of conformity with this dietary pattern; a high score suggested good conformity with that pattern. Furthermore, complementary analysis was performed to assess the robustness of the dietary patterns identified, in which the original absolute food intake was measured in grams/day in factor analysis.

\section{Data Collection of Clinical Information and Breast Cancer Outcome}

Hospital medical records were reviewed to obtain diagnosis and treatment information. These included age at diagnosis, tumor histology, AJCC stage version 7.0, ${ }^{24}$ estrogen receptor (ER) and progesterone receptor (PR) status, HER2 status, and treatment history (mastectomy or breast conserving surgery, adjuvant chemotherapy, radiotherapy, endocrine therapy and anti-HER2 targeted therapy). Information about disease progression and survival status was collected by reviewing medical records annually. In addition, interviewers also asked patients about their disease status during follow-ups through face-to-face interview. For those who defaulted follow-up, telephone contacts were made to the patients or their next of kin, and their statuses were updated. In this study, patients who had ipsilateral/contralateral/local/ regional invasive recurrence, distant recurrence or secondary primary breast cancer were defined as recurrence. Overall mortality was defined as death from any cause. Breast cancer-specific mortality was defined as breast cancer-related 
death. Mortality from other causes was determined by excluding mortality from breast cancer.

\section{Statistical Analysis}

Data on sociodemographic and clinical characteristics were summarized as patient number (n) and percentages (\%) for categorical variables, and means with standard deviations for continuous variables. Patients were categorized into three groups according to the tertiles of factor score in each dietary pattern (tertile 1 , tertile 2 and tertile 3). Dietary characteristics of participants were compared among three groups using one-way ANOVA. Cox proportional hazards models were used to investigate associations between dietary patterns and time to outcome. In multivariable model, adjustments were made for age at 18-month follow-up (years, continuous), total number of comorbidities at 18 -month follow-up $(0,1, \geq 2)$, stage at diagnosis (I, II, III, I-III without detail), ER status (positive, negative, missing), PR status (positive, negative, missing), HER2 status (positive, negative, missing), histology [invasive ductal carcinoma (IDC), invasive lobular carcinoma (ILC), others], chemotherapy (yes, no), radiotherapy (yes, no), adjuvant hormonal therapy usage at 18-month follow-up (yes, no), menopausal status at 18month follow-up (pre-menopausal, peri/post-menopausal) , BMI group at 18-month follow-up $(<18.5,18.5-22.9$, $23-24.9$ and $\geq 25 \mathrm{~kg} / \mathrm{m}^{2}$ ), level of physical activity at 18 month follow-up (MET-hours/week, continuous) and total energy intake at 18 -month follow-up (kcal/day, continuous). Person-time was calculated from the date of 18 months follow-up until event/censoring. In analyses of breast cancer-specific mortality, subjects who died of causes other than breast cancer were censored. Schoenfeld residual-based test was used to test for violations of proportional hazards. ${ }^{30}$ All analyses were performed using SPSS 26.0; and $P$ value $<0.05$ based on a two-sided analysis was considered statistically significant.

\section{Results}

\section{Patients' Socio-Demographic, Breast Cancer and Lifestyle Characteristics}

Of the 1310 patients who completed interview at 18-month follow-up, 1226 patients were included in the present analysis. Patients who were excluded had an implausible dietary intake (energy intake estimates $<500$ or $>4000 \mathrm{kcal}$ per day, $\mathrm{n}=4)$, incomplete QoL data $(\mathrm{n}=3)$ or had in-situ disease $(n=77)$. Patients who were included in this study showed similar baseline characteristics as in the whole cohort. The last follow-up date of this study was December 31, 2018, and median follow-up time was 54.1 months (range: 3.1-79.9). In total, 165 patients had a breast cancer recurrence. For overall mortality, 98 deaths occurred, 88 were due to breast cancer and 10 were due to other causes.

The baseline socio-demographic, clinical and lifestyle characteristics of patients included in this analysis are provided in Table 1. The mean age of the patients at diagnosis was 52.3 years [standard deviation (SD): 9.0]. Nearly half $(45.6 \%)$ of patients were within normal BMI, $20.7 \%$ were overweight, and $28.5 \%$ were obese. Majority (61.0\%) of the participants had no comorbidity. Nearly $80 \%$ of patients had parity. At diagnosis, more than half $(51.5 \%)$ of the patients were pre-menopausal, while the corresponding figure decreased to $19.7 \%$ at 18 month follow-up. The proportions of stage I, II and III at diagnosis were $31.6 \%, 48.2 \%$ and $19.7 \%$, respectively. Nearly $90 \%$ of patients had IDC. The proportions of patients who received adjuvant chemotherapy, radiotherapy and endocrine therapy were $81.8 \%, 70.6 \%$ and $76.5 \%$, respectively. The mean level of physical activity was 10.1 MET-hours/week (SD: 13.4), and mean energy intake was $1361.7 \mathrm{kcal} /$ day (SD: 392.8).

\section{Two Major Dietary Patterns Identified}

Two major dietary patterns were identified by factor analysis (Table 2), and absolute values $>0.25$ were shown in bold. The first pattern, termed "Western dietary pattern", was characterized by high factor loadings for refined grain, red meat, oil, fish and seafood, cakes and snacks, processed meat and eggs. The second, termed "healthy dietary pattern", was characterized by high factor loadings for leafy vegetables, non-leafy vegetables, fruits, potatoes and legumes. These two factors explained $38.38 \%$ of the total variance ( $26.23 \%$ and $12.15 \%$, respectively).

\section{Dietary Characteristics of Each Dietary Pattern}

The dietary characteristics of each dietary pattern are summarized in Table 3. Women with high "Western dietary pattern" scores were also characterized by higher intake of fat and cholesterol. In contrast, women with high "healthy dietary pattern" scores consumed higher amounts of protein and fiber. 
Table I Socio-Demographic and Clinical Characteristics of Patients $(n=1226)$

\begin{tabular}{|c|c|c|}
\hline Characteristics & Number of Patients & Frequency, \% \\
\hline Age at diagnosis, years, mean (SD) & \multicolumn{2}{|l|}{$52.3(9.0)$} \\
\hline Age at 18-minth follow-up, years, mean (SD) & \multicolumn{2}{|l|}{$53.8(9.0)$} \\
\hline Follow-up time, months, median (range) & \multicolumn{2}{|l|}{$54.1(3.1-79.9)$} \\
\hline Education level & & \\
\hline High school or below & 1049 & 85.6 \\
\hline College or above & 177 & 14.4 \\
\hline \multicolumn{3}{|l|}{ Marital status } \\
\hline Married or cohabitation & 867 & 70.7 \\
\hline Unmarried or divorced or widowed & 359 & 29.3 \\
\hline \multicolumn{3}{|l|}{ Household income, HKD/month } \\
\hline$<15,000$ & 576 & 47.0 \\
\hline $15,000-29,999$ & 388 & 31.6 \\
\hline$\geq 30,000$ & 262 & 21.4 \\
\hline \multicolumn{3}{|l|}{ BMI at follow-up, $\mathrm{kg} / \mathrm{m}^{2}$} \\
\hline Underweight $(<18.5)$ & 64 & 5.2 \\
\hline Normal (18.5-22.9) & 559 & 45.6 \\
\hline Overweight (23-24.9) & 254 & 20.7 \\
\hline Obese $(\geq 25)$ & 349 & 28.5 \\
\hline \multicolumn{3}{|l|}{ Number of comorbidities } \\
\hline None & 748 & 61.0 \\
\hline 1 & 318 & 25.9 \\
\hline$\geq 2$ & 160 & 13.1 \\
\hline \multicolumn{3}{|l|}{ Parity, \% } \\
\hline 0 & 274 & 22.3 \\
\hline 1 & 280 & 22.8 \\
\hline 2 & 456 & 37.2 \\
\hline$\geq 3$ & 216 & 17.6 \\
\hline \multicolumn{3}{|l|}{ Menopausal status at diagnosis } \\
\hline Premenopausal & 631 & 51.5 \\
\hline Postmenopausal & 595 & 48.5 \\
\hline \multicolumn{3}{|l|}{ Menopausal status at follow-up } \\
\hline Premenopausal & 242 & 19.7 \\
\hline Postmenopausal & 948 & 80.3 \\
\hline \multicolumn{3}{|l|}{ AJCC stage at diagnosis } \\
\hline 1 & 387 & 31.6 \\
\hline II & 591 & 48.2 \\
\hline III & 242 & 19.7 \\
\hline I-III without detail & 6 & 0.5 \\
\hline \multicolumn{3}{|l|}{ Histology } \\
\hline IDC & 1099 & 89.6 \\
\hline ILC & 38 & 3.1 \\
\hline Others & 89 & 7.3 \\
\hline
\end{tabular}

(Continued) 
Table I (Continued).

\begin{tabular}{|c|c|c|}
\hline Characteristics & Number of Patients & Frequency, \% \\
\hline \multicolumn{3}{|l|}{ ER status } \\
\hline Positive & 902 & 73.6 \\
\hline Negative & 292 & 23.8 \\
\hline Missing & 32 & 2.6 \\
\hline \multicolumn{3}{|l|}{ PR status } \\
\hline Positive & 692 & 56.4 \\
\hline Negative & 497 & 40.5 \\
\hline Missing & 37 & 3.0 \\
\hline \multicolumn{3}{|l|}{ HER2 status } \\
\hline Positive & 333 & 27.2 \\
\hline Negative & 852 & 69.5 \\
\hline Missing & 41 & 3.3 \\
\hline \multicolumn{3}{|l|}{ Type of surgery } \\
\hline Mastectomy & 795 & 64.8 \\
\hline Conservation & 431 & 35.2 \\
\hline \multicolumn{3}{|l|}{ Chemotherapy } \\
\hline Yes & 994 & 81.1 \\
\hline No & 232 & 18.9 \\
\hline \multicolumn{3}{|l|}{ Radiation therapy } \\
\hline Yes & 865 & 70.6 \\
\hline No & 361 & 29.4 \\
\hline \multicolumn{3}{|l|}{ Hormone therapy } \\
\hline Yes & 938 & 76.5 \\
\hline No & 288 & 23.5 \\
\hline Physical activity level, MET-hours/week, mean (SD) & \multicolumn{2}{|l|}{$10.1(13.4)$} \\
\hline Energy intake, kcal/day, mean (SD) & \multicolumn{2}{|l|}{$1361.7(392.8)$} \\
\hline
\end{tabular}

Abbreviations: SD, standard deviation; HKD, Hong Kong dollars; BMI, body mass index; AJCC, American Joint Committee on cancer; IDC, invasive ductal carcinoma; ILC, invasive lobular carcinoma; ER, estrogen receptor; PR, progesterone receptor; HER 2, human epidermal-growth-factor receptor 2; MET, metabolic equivalent of task.

\section{Clinical Outcome According to the Tertiles of Factor Score in Each Dietary Pattern}

In multivariate-adjusted analyses, "Western dietary pattern" was not significantly associated with breast cancer recurrence (Table $4 ; P_{\text {trend }}=0.89$ ). In cox proportional hazards models, the tertiles of "Western dietary pattern" was not associated with overall mortality $\left(P_{\text {trend }}=0.48\right)$. Similarly, a higher intake of the "Western dietary pattern" was not associated with breast cancer-specific mortality $\left(P_{\text {trend }}=0.75\right)$.

The association between "healthy dietary pattern" and breast cancer outcome was also investigated by Cox proportional hazards models (Table 5). No association was observed between this dietary pattern and breast cancer recurrence $\left(P_{\text {trend }}=0.99\right)$. In addition, the highest tertile of "healthy dietary pattern" was not related to overall death $\left(P_{\text {trend }}=0.20\right)$ or death from breast cancer $\left(P_{\text {trend }}=0.30\right)$. Similar analyses were undertaken among patients with IDC (Supplementary Table 1, 2), while patients with invasive lobular carcinoma (ILC, $n=38$ ) and others' histology $(n=89)$ were not analyzed due to small patient number. Furthermore, stratification analyses were undertaken by hormone receptor (HR) status (HR positive vs HR negative; patients with unknown HR status were not included into analysis, $\mathrm{n}=32$; Supplementary Table 3-6). The results were constant across all tumor types.

\section{Discussion}

In this longitudinal cohort study of Chinese early-stage breast cancer patients, patients were periodically interviewed at four 
Table 2 Food Group Loadings for the Two Major Dietary Patterns Identified by Principal Component Analysis

\begin{tabular}{|l|l|l|}
\hline Foods/Food Groups & Factor I Western Dietary Pattern & Factor 2 Healthy Dietary Pattern \\
\hline Refined grain & 0.72 & 0.24 \\
Whole grain & -0.33 & 0.13 \\
Cakes and snacks & 0.30 & 0.03 \\
Poultry & 0.16 & -0.03 \\
Red meat & 0.48 & 0.04 \\
Processed meat & 0.27 & -0.07 \\
Fish and seafood & 0.41 & 0.14 \\
Eggs & 0.26 & 0.04 \\
Dairy products & 0.24 & -0.05 \\
Leaf vegetables & -0.29 & 0.93 \\
Non-leaf vegetables & 0.08 & 0.49 \\
Potato & -0.03 & 0.31 \\
Fruits & 0.01 & 0.39 \\
Legumes & 0.05 & 0.28 \\
Soya & 0.24 & 0.18 \\
Oil & 0.41 & 0.12 \\
Nuts & 0.06 & 0.23 \\
Variance explained (\%) & 26.23 & 12.15 \\
\hline
\end{tabular}

Note: Absolute values of factor loadings $>0.25$ are shown in bold.

time-points, during which they were prospectively followed up for disease recurrence and death status. Based on dietary assessment at 18-month follow-up, this study investigated dietary pattern and breast cancer outcome among Chinese breast cancer patients. In this study, two dietary patterns were identified. Cox proportional hazards models were used to investigate the correlations between dietary pattern and outcomes of breast cancer. Neither dietary pattern was associated with risk of breast cancer recurrence, all-causes death or death from breast cancer.

A number of studies and meta-analyses have investigated the association between dietary patterns and the risk of breast cancer. ${ }^{13-16}$ In a recently published metaanalysis, Western dietary pattern has been suggested to be associated with increased risk of both IDC and ILC of the breast, while Mediterranean diet pattern may be associated with decreased risk. ${ }^{16}$

Not having focused on individual dietary components, this study analyzed dietary pattern to investigate the overall dietary habits after breast cancer diagnosis. Two dietary patterns, termed "Western dietary pattern" and "healthy dietary pattern", have been identified. They have similar dietary characteristics that described in two previous studies among women with breast cancer in the US, ie, the Nurses' Health Study (NHS) and Life After Cancer Epidemiology (LACE) Study. ${ }^{17,18}$ The present results are consistent with the findings of the NHS, which showed that Western and prudent dietary patterns were unrelated to all-cause or breast cancer-specific mortality. ${ }^{17}$ However, the association between dietary patterns and death from causes other than breast cancer was different. The NHS and LACE studies both found that higher intakes of the prudent pattern and lower intakes of the Western pattern might reduce the risk of mortality from causes unrelated to breast cancer. This inconsistency may be explained by different rates of mortality from causes other than breast cancer. Even though the three studies all investigated dietary intake during immediate survival, from 1.5 to 3.25 years after cancer diagnosis, the causes of mortality were different. After a median follow-up of 4.5 years, the major causes of death were breast cancer $(88 / 98,89.8 \%)$ in the present study, while only a small proportion of patients died of other causes $(10 / 98$, $10.2 \%$ ). Of note, the corresponding figures of the two studies in the US were different: $58.5 \%$ and $41.5 \%$ (after a median of 9 years of follow-up) in NHS, 56.6\% and $44.4 \%$ (after a median of 6.3 years of follow-up) in LACE study, respectively. The lower proportion of patients having died of other causes in this study may be partly explained by the following reasons. Firstly, the peak age incidence of breast cancer was much younger in East Asian than Western counterparts; that is, the peak age was around 50 years in Hong Kong, Japan, Korea, and Taiwan, in contrast to approximately 70 years in the US. ${ }^{9}$ In fact, the mean ages of the present cohort and the two US cohorts also reflect 
Table 3 Dietary Characteristics According to the Tertiles of Each Dietary Pattern Score $(n=1226)$

\begin{tabular}{|c|c|c|c|c|c|c|c|c|}
\hline & \multicolumn{4}{|c|}{ Western Dietary Pattern } & \multicolumn{4}{|c|}{ Healthy Dietary Pattern } \\
\hline & $\begin{array}{l}\text { Tertile I } \\
(n=408)\end{array}$ & $\begin{array}{l}\text { Tertile } 2 \\
(n=4 \mid 0)\end{array}$ & $\begin{array}{l}\text { Tertile } 3 \\
(n=408)\end{array}$ & $P_{\text {trend }}$ & $\begin{array}{l}\text { Tertile I } \\
(n=409)\end{array}$ & $\begin{array}{l}\text { Tertile } 2 \\
(n=409)\end{array}$ & $\begin{array}{l}\text { Tertile } 3 \\
(n=408)\end{array}$ & $P_{\text {trend }}$ \\
\hline \multicolumn{9}{|c|}{ Food groups, grams/1000kcals/day, mean } \\
\hline Refined grain & 313.30 & 335.59 & 335.80 & $<0.01$ & 334.27 & 334.11 & 316.33 & 0.02 \\
\hline Whole grain & 23.53 & $\mid \mathrm{I} .4 \mathrm{I}$ & 6.55 & $<0.01$ & 13.15 & 13.55 & 14.79 & 0.17 \\
\hline Cakes and snacks & 5.97 & 7.41 & 8.99 & $<0.01$ & 8.46 & 7.09 & 6.82 & $<0.01$ \\
\hline Poultry & 4.63 & 5.30 & 6.16 & 0.04 & 6.59 & 5.41 & 4.10 & $<0.01$ \\
\hline Red meat & 35.22 & 44.95 & 50.83 & $<0.01$ & 45.57 & 44.85 & 40.58 & 0.02 \\
\hline Processed meat & 1.32 & 1.87 & 3.00 & $<0.01$ & 2.73 & 1.96 & 1.50 & $<0.01$ \\
\hline Fish and seafood & 43.95 & 44.00 & 43.22 & 0.73 & 41.38 & 45.06 & 44.72 & 0.12 \\
\hline Eggs & 11.99 & 12.22 & 12.97 & 0.19 & 13.47 & 12.83 & 10.87 & $<0.01$ \\
\hline Dairy products & $|2.5|$ & 12.22 & 12.25 & 0.97 & 13.43 & 11.68 & II.87 & 0.27 \\
\hline Leaf vegetables & 322.64 & 207.93 & 157.13 & $<0.01$ & 156.55 & 225.46 & 305.76 & $<0.01$ \\
\hline $\begin{array}{l}\text { Non-leaf } \\
\text { vegetables }\end{array}$ & 77.59 & 63.77 & 58.08 & $<0.01$ & 49.55 & 65.39 & 84.53 & $<0.01$ \\
\hline Potato & 23.92 & 17.91 & 14.58 & $<0.01$ & 12.90 & 19.40 & 24.13 & $<0.01$ \\
\hline Fruits & 186.33 & 144.16 & 123.44 & $<0.01$ & 139.16 & 152.58 & 162.18 & $<0.01$ \\
\hline Legumes & 7.27 & 6.70 & 6.27 & 0.10 & 4.95 & 6.57 & 8.73 & $<0.01$ \\
\hline Soya & 33.34 & 36.96 & 34.79 & 0.62 & 34.22 & 33.59 & 37.29 & 0.29 \\
\hline Oil & 0.85 & 0.92 & 1.01 & $<0.01$ & 1.02 & 0.90 & 0.86 & $<0.01$ \\
\hline Nuts & 6.74 & 5.80 & 4.76 & $<0.01$ & 4.22 & 5.17 & 7.91 & $<0.01$ \\
\hline \multicolumn{9}{|c|}{ Nutrients, nutrient/ $1000 \mathrm{kcals} /$ day, mean } \\
\hline $\begin{array}{l}\text { Energy intake, } \\
\text { kcal }\end{array}$ & 1083.69 & 1314.73 & 1686.77 & $<0.01$ & II55.07 & 1354.67 & 1575.73 & $<0.01$ \\
\hline Protein, g & 43.55 & 42.67 & 42.27 & $<0.01$ & 41.16 & 43.07 & 44.26 & $<0.01$ \\
\hline Fat, g & 32.32 & 34.54 & 36.62 & $<0.01$ & 35.36 & 33.94 & 34.17 & 0.03 \\
\hline Carbohydrate, g & 143.82 & 137.56 & 132.09 & $<0.01$ & 136.10 & 138.69 & 138.68 & 0.08 \\
\hline Fiber, $g$ & 12.70 & 10.37 & 9.23 & $<0.01$ & 9.30 & 10.68 & 12.32 & $<0.01$ \\
\hline Cholesterol, g & 144.27 & $|56.7|$ & 167.33 & $<0.01$ & 165.09 & 160.14 & 143.04 & $<0.01$ \\
\hline
\end{tabular}

such discrepancy, which were 52 years compared to 58-59 years, respectively. It is more likely that elderly patients die of causes other than breast cancer, eg cardiovascular disease. ${ }^{10}$ Secondly, distinctive racial and potential molecular profiles may result in different clinical outcomes. Thirdly, differences exist between the timing of diagnosis and treatment in these three cohorts. The present cohort enrolled patients between 2011 and 2014, while the NHS and the LACE studies included patients diagnosed decades ago, from 1982 to 1998 and from 2000 to 2002, respectively. ${ }^{17,18}$ In recent decades, treatment strategies have been revolutionized, clinicians have aroused more 
Table 4 Cox Proportional Hazards Models to Investigate Association of Tertiles of "Western Dietary Pattern" and Outcomes of Breast Cancer $(n=1226)$

\begin{tabular}{|c|c|c|c|c|c|c|c|c|c|c|}
\hline \multirow[t]{2}{*}{ Tertiles } & \multirow{2}{*}{$\begin{array}{l}\text { No. of } \\
\text { Patients }\end{array}$} & \multicolumn{3}{|c|}{ Recurrence } & \multicolumn{3}{|c|}{ Overall Death } & \multicolumn{3}{|c|}{ Death from Breast Cancer } \\
\hline & & $\begin{array}{l}\text { No. of } \\
\text { Events }\end{array}$ & $\begin{array}{l}\text { HR }(95 \% \\
\mathrm{Cl})\end{array}$ & $P_{\text {trend }}$ & $\begin{array}{l}\text { No. of } \\
\text { Events }\end{array}$ & $\begin{array}{l}\text { HR }(95 \% \\
\text { Cl) }\end{array}$ & $P_{\text {trend }}$ & $\begin{array}{l}\text { No. of } \\
\text { Events }\end{array}$ & $\begin{array}{l}\text { HR }(95 \% \\
\text { Cl) }\end{array}$ & $P_{\text {trend }}$ \\
\hline \multicolumn{11}{|c|}{ Unadjusted Model } \\
\hline Tertiles I & 408 & 50 & I [Reference] & \multirow[t]{3}{*}{0.80} & 33 & I [Reference] & \multirow[t]{3}{*}{0.64} & 28 & I [Reference] & \multirow[t]{3}{*}{0.94} \\
\hline Tertiles 2 & 410 & 60 & $\begin{array}{l}1.20 \\
(0.81-1.78)\end{array}$ & & 35 & $\begin{array}{l}1.01 \\
(0.62-1.63)\end{array}$ & & 32 & $\begin{array}{l}1.09 \\
(0.65-1.81)\end{array}$ & \\
\hline Tertiles 3 & 408 & 55 & $\begin{array}{l}1.06 \\
(0.70-1.59)\end{array}$ & & 30 & $\begin{array}{l}0.89 \\
(0.54-1.46)\end{array}$ & & 28 & $\begin{array}{l}0.98 \\
(0.58-1.66)\end{array}$ & \\
\hline \multicolumn{11}{|l|}{ Model I } \\
\hline Tertiles I & 408 & 50 & I [Reference] & \multirow[t]{3}{*}{0.52} & 33 & I [Reference] & \multirow[t]{3}{*}{0.32} & 28 & I [Reference] & \multirow[t]{3}{*}{0.38} \\
\hline Tertiles 2 & 410 & 60 & $\begin{array}{l}1.08 \\
(0.72-1.62)\end{array}$ & & 35 & $\begin{array}{l}0.89 \\
(0.55-1.45)\end{array}$ & & 32 & $\begin{array}{l}0.94 \\
(0.56-1.58)\end{array}$ & \\
\hline Tertiles 3 & 408 & 55 & $\begin{array}{l}0.88 \\
(0.58-1.33)\end{array}$ & & 30 & $\begin{array}{l}0.78 \\
(0.47-1.29)\end{array}$ & & 28 & $\begin{array}{l}0.79 \\
(0.46-1.35)\end{array}$ & \\
\hline \multicolumn{11}{|l|}{ Model 2} \\
\hline Tertiles I & 408 & 50 & I [Reference] & \multirow[t]{3}{*}{0.89} & 33 & I [Reference] & \multirow[t]{3}{*}{0.48} & 28 & I [Reference] & \multirow[t]{3}{*}{0.75} \\
\hline Tertiles 2 & 410 & 60 & $\begin{array}{l}1.14 \\
(0.74-1.74)\end{array}$ & & 35 & $\begin{array}{l}0.88 \\
(0.53-1.49)\end{array}$ & & 32 & $\begin{array}{l}0.96 \\
(0.55-1.67)\end{array}$ & \\
\hline Tertiles 3 & 408 & 55 & $\begin{array}{l}1.03 \\
(0.61-1.75)\end{array}$ & & 30 & $\begin{array}{l}0.79 \\
(0.4|-| .52)\end{array}$ & & 28 & $\begin{array}{l}0.90 \\
(0.45-1.77)\end{array}$ & \\
\hline
\end{tabular}

Notes: Cox proportional hazards models were used to investigate association of tertiles of dietary patterns and time to outcome. Model I were adjusted by age at I8month follow-up (continuous), stage at diagnosis, ER status, PR status, HER2 status, histology, chemotherapy, radiotherapy and adjuvant hormonal therapy usage at I8-month follow-up. Model 2 were adjusted by age at 18-month follow-up (continuous), total number of comorbidities at I8-month follow-up, stage at diagnosis, ER status, PR status, HER2 status, histology, chemotherapy, radiotherapy, adjuvant hormonal therapy usage at I8-month follow-up, menopausal status at I8-months follow-up, BMI at I8-month follow-up (continuous), level of physical activity at 18-month follow-up (continuous) and total energy intake at I8-month follow-up (continuous).

Abbreviations: HR, hazard ratio; $\mathrm{Cl}$, confidence interval; ER, estrogen receptor; PR, progesterone receptor; HER 2, human epidermal-growth-factor receptor 2; BMI, body mass index.

attention to manage patients' comorbidities and options of treatment regimens with less cardiotoxic agents have been considered. Such changes in practice may help breast cancer patients reduce the risk of death from other causes.

Several studies have also evaluated whether adherence to dietary recommendations was associated with breast cancer outcomes. The Women's Health Initiative (WHI) and the Health, Eating, Activity, and Lifestyle (HEAL) studies both enrolled women with breast cancer in the US and showed that higher adherence to Healthy Eating Index-2005 (HEI-2005) after breast cancer diagnosis was associated with reduced risk of overall mortality. ${ }^{31,32}$ However, the associations between better quality diets and death from breast cancer were inconsistent with both null and protective effects being reported. ${ }^{31,32}$ Recently, another report from the Shanghai Breast Cancer Survival
Study (SBCSS) has also investigated possible benefits of adherence to dietary recommendations on outcomes of breast cancer in Chinese women. Using dietary data assessed at the 5-year post-diagnosis, this study constructed adherence scores to Chinese Food Pagoda (CHFP)-2007, CHFP-2016, modified Dietary Approaches to Stop Hypertension (DASH), and HEI-2015. The results suggested that higher adherence scores to CHFP and DASH were related to reduced risk of overall death and breast cancer-specific recurrence or death. However, associations with adherence to HEI-2015 were not significant. ${ }^{20}$ Although the above-mentioned study and the present study both examined the potential effect of dietary intake and outcomes of breast cancer in Chinese women, there are several differences between them. Firstly, different methods were applied to evaluate dietary 
Table 5 Cox Proportional Hazards Models to Investigate Association of Tertiles of "Healthy Dietary Pattern" and Outcome of Breast Cancer $(n=1226)$

\begin{tabular}{|c|c|c|c|c|c|c|c|c|c|c|}
\hline \multirow[t]{2}{*}{ Tertiles } & \multirow{2}{*}{$\begin{array}{l}\text { No. of } \\
\text { Patients }\end{array}$} & \multicolumn{3}{|c|}{ Recurrence } & \multicolumn{3}{|c|}{ Overall Death } & \multicolumn{3}{|c|}{ Death from Breast Cancer } \\
\hline & & $\begin{array}{l}\text { No. of } \\
\text { Events }\end{array}$ & $\begin{array}{l}\text { HR }(95 \% \\
\text { CI) }\end{array}$ & $P_{\text {trend }}$ & $\begin{array}{l}\text { No. of } \\
\text { Events }\end{array}$ & $\begin{array}{l}\text { HR }(95 \% \\
\mathrm{CI})\end{array}$ & $P_{\text {trend }}$ & $\begin{array}{l}\text { No. of } \\
\text { Events }\end{array}$ & $\begin{array}{l}\text { HR }(95 \% \\
\mathrm{CI})\end{array}$ & $P_{\text {trend }}$ \\
\hline \multicolumn{11}{|c|}{ Unadjusted Model } \\
\hline Tertiles I & 409 & 61 & $\begin{array}{l}\text { I } \\
\text { [Reference] }\end{array}$ & \multirow[t]{3}{*}{0.41} & 31 & $\begin{array}{l}\text { I } \\
\text { [Reference] }\end{array}$ & \multirow[t]{3}{*}{0.59} & 28 & $\begin{array}{l}\text { I } \\
\text { [Reference] }\end{array}$ & \multirow[t]{3}{*}{0.66} \\
\hline Tertiles 2 & 409 & 49 & $\begin{array}{l}0.80 \\
(0.54-1.19)\end{array}$ & & 32 & $\begin{array}{l}0.99 \\
(0.60-1.63)\end{array}$ & & 29 & $\begin{array}{l}0.99 \\
(0.59-1.68)\end{array}$ & \\
\hline Tertiles 3 & 408 & 55 & $\begin{array}{l}0.85 \\
(0.58-1.26)\end{array}$ & & 35 & $\begin{array}{l}1.14 \\
(0.70-1.85)\end{array}$ & & 31 & $\begin{array}{l}1.12 \\
(0.67-1.87)\end{array}$ & \\
\hline \multicolumn{11}{|l|}{ Model I } \\
\hline Tertiles I & 409 & 61 & $\begin{array}{l}\text { I } \\
\text { [Reference] }\end{array}$ & \multirow[t]{3}{*}{0.50} & 31 & $\begin{array}{l}\text { I } \\
\text { [Reference] }\end{array}$ & \multirow[t]{3}{*}{0.46} & 28 & $\begin{array}{l}\text { I } \\
\text { [Reference] }\end{array}$ & \multirow[t]{3}{*}{0.67} \\
\hline Tertiles 2 & 409 & 49 & $\begin{array}{l}0.80 \\
(0.54-1.19)\end{array}$ & & 32 & $\begin{array}{l}1.03 \\
(0.62-1.72)\end{array}$ & & 29 & $\begin{array}{l}0.96 \\
(0.57-1.63)\end{array}$ & \\
\hline Tertiles 3 & 408 & 55 & $\begin{array}{l}0.88 \\
(0.59-1.30)\end{array}$ & & 35 & $\begin{array}{l}1.20 \\
(0.74-1.96)\end{array}$ & & 31 & $\begin{array}{l}1.12 \\
(0.67-1.88)\end{array}$ & \\
\hline \multicolumn{11}{|l|}{ Model 2} \\
\hline Tertiles I & 409 & 61 & $\begin{array}{l}\text { I } \\
\text { [Reference] }\end{array}$ & \multirow[t]{3}{*}{0.99} & 31 & $\begin{array}{l}\text { I } \\
\text { [Reference] }\end{array}$ & \multirow[t]{3}{*}{0.20} & 28 & $\begin{array}{l}\text { I } \\
\text { [Reference] }\end{array}$ & \multirow[t]{3}{*}{0.30} \\
\hline Tertiles 2 & 409 & 49 & $\begin{array}{l}0.86 \\
(0.57-1.30)\end{array}$ & & 32 & $\begin{array}{l}\text { I.15 } \\
(0.68-1.93)\end{array}$ & & 29 & $\begin{array}{l}1.07 \\
(0.62-1.86)\end{array}$ & \\
\hline Tertiles 3 & 408 & 55 & $\begin{array}{l}1.01 \\
(0.64-1.59)\end{array}$ & & 35 & $\begin{array}{l}1.45 \\
(0.82-2.56)\end{array}$ & & 31 & $\begin{array}{l}1.37 \\
(0.76-2.49)\end{array}$ & \\
\hline
\end{tabular}

Notes: Cox proportional hazards models were used to investigate association of tertiles of dietary patterns and time to outcome. Model I were adjusted by age at 18 month follow-up (continuous), stage at diagnosis, ER status, PR status, HER2 status, histology, chemotherapy, radiotherapy and adjuvant hormonal therapy usage at I8-month follow-up. Model 2 were adjusted by age at 18-month follow-up (continuous), total number of comorbidities at I8-month follow-up, stage at diagnosis, ER status, PR status, HER2 status, histology, chemotherapy, radiotherapy, adjuvant hormonal therapy usage at I8-month follow-up, menopausal status at I8-month follow-up, BMI at I8-month follow-up (continuous), level of physical activity at I8-month follow-up (continuous) and total energy intake at I8-month follow-up (continuous).

Abbreviations: $\mathrm{HR}$, hazard ratio; $\mathrm{Cl}$, confidence interval; ER, estrogen receptor; PR, progesterone receptor; HER 2, human epidermal-growth-factor receptor 2; BMI, body mass index.

intake. The present study investigated patients' adherence to two specific dietary patterns, while the SBCSS evaluated the adherence to several dietary guidelines. Secondly, the two studies enrolled patients diagnosed at different periods of time; with the present study having enrolled patients who were diagnosed nearly 10 years later (from 2011 to 2014, as opposed to being from 2002 to 2006 for the SBCSS). Treatment and management strategies for breast cancer have improved during this period, which might have an impact on the causes of mortality. In addition, the follow-up time-points also differed. There is a possibility that dietary intake has different effects on short- and long-term breast cancer outcomes. Thirdly, these two studies assessed patients' dietary intakes at different survival intervals, 1.5 years and 5 years, respectively. Fourthly, the two studies enrolled Chinese women in different areas, Hong Kong and Shanghai; although both are big cities in China, lifestyle habits may be different. Also, the medical systems in the two cities, ie, the policy for drug approval and medical expenditure systems, were different. These could possibly impact on patients' outcome.

Apart from observational studies, two large interventional trials have investigated the effect of diets low in fat 
and/or high in vegetables, fruits and fiber on outcomes of breast cancer. ${ }^{33,34}$ In the Women's Intervention Nutrition study (WINS), a total of 2437 women with early-stage breast cancer were randomly assigned to a dietary intervention group or a control group. ${ }^{33}$ After a median followup of 5 years, participants randomized to low-fat diet had a 6-pound lower in mean body weight than the control group. The low-fat diet was also related to a reduced relative risk of recurrence by $24 \% .{ }^{33}$ The other study, the Women's Healthy Eating and Living (WHEL) study, assessed the effect of a diet very high in vegetables, fruits and fiber while low in fat on breast cancer prognosis. ${ }^{34}$ After a mean follow-up of 7.3 years, the results showed that such interventional dietary adaptation did not reduce the risk of breast cancer recurrence or mortality. ${ }^{34}$ These two randomized trials reported inconsistent results; as such, dietary modification, to date, cannot be translated into clinical practice.

The mechanisms for associations between specific dietary pattern and cancer outcome are not entirely understood. It has been reported that dietary components could modify inflammatory status through both pro-inflammatory and antiinflammatory mechanisms, ${ }^{35-37}$ which may be associated with breast cancer growth. ${ }^{38}$ In the present study, although no significant association was found between the two dietary patterns and breast cancer outcome or all-cause mortality, healthy dietary habits remain to be encouraged for all breast cancer survivors, as it may reduce the risk of mortality from other causes. Several guidelines have established dietary recommendations for cancer survivors, eg, the American Society of Clinical Oncology (ASCO) has recommended that primary care clinicians should counsel breast cancer survivors to achieve a dietary pattern that is high in vegetables, fruits, whole grains and legumes while low in saturated fat. ${ }^{39}$

Based on a longitudinal study design, this study prospectively collected patients' dietary intake and obtained complete data on cancer recurrence and mortality. In addition, this study comprehensively recorded information on social-demographic, breast cancer characteristics and treatments information; these have allowed us to adjust potential confounders in the survival analysis. Furthermore, dietary assessments of all participants were homogeneously undertaken in a narrow window using a validated FFQ. The 18-month follow-up assessment was an important time-point, which evaluate patients' dietary intake during 6 to 18 months after cancer diagnosis. This was the time when breast patients had just completed intense anti-cancer therapy, when they started to adjust to live as a cancer survivor. There are a few limitations in the present study. Firstly, no association was found between the tested dietary patterns and outcomes in the present analysis, this might be due to the relatively short follow-up time, with only 165 patients having developed recurrence and 98 deaths being recorded. As the survival of early-stage breast cancer has improved, longer follow-up time for survival analysis is essential. In addition, since the number of non-breast cancer-related deaths was very few, the data were not mature enough to adequately analyze this aspect. Secondly, during our enrollment procedure, around $27 \%$ of the eligible participants refused to participate in this study. This might result in a selection bias for the study cohort. Thirdly, a number of patients might have changed their diet between the follow-ups. As the present study aimed to investigate the association between dietary intake assessed at 18-month follow-up and outcomes of breast cancer, we have not taken into account the changes in patients' diet between the follow-ups. However, our previously published data suggested that breast cancer survivors in this cohort would have made dietary changes at the time of diagnosis or soon thereafter, with no major change observed at 36-months. ${ }^{21}$ Hence, we believe that the dietary intake at 18-month follow-up could reflect patients' dietary habits at post-diagnosis to a great extent. Last but not least, similar to other studies on dietary patterns, some arbitrary decisions existed in identifying dietary patterns, eg, food grouping, method of factor rotation and labeling of dietary patterns. ${ }^{40}$ Furthermore, the resulting dietary patterns depend heavily on the way the diet is now being quantified, and the identified dietary patterns may vary by using various operationalizations of dietary variables.

\section{Conclusions}

Based on a longitudinal cohort study, this was the first study to investigate post-diagnosis dietary patterns and outcomes of breast cancer among Chinese breast cancer patients. Two dietary patterns have been identified, namely "Western dietary pattern" and "healthy dietary pattern". Cox proportional hazards models have shown that neither of these dietary patterns was associated with risk of breast cancer recurrence, all-causes death, or death from breast cancer. Further prospective follow-up is still needed to further confirm the association between specific dietary patterns and breast cancer-specific outcomes and allcause mortality. 


\section{Data Sharing Statement}

Data are available on reasonable request.

\section{Ethics Approval and Informed Consent}

The study was conducted in accordance with the Declaration of Helsinki, and approved by the Joint CUHKNTEC Clinical Research Ethics Committee and the KWC Research Ethics Committee of the Chinese University of Hong Kong and the Hong Kong Hospital Authority. Informed consent was obtained from all patients and patient information was anonymized and de-identified prior to analysis.

\section{Funding}

This work was supported by World Cancer Research Fund International (Grant Number WCRF 2010/249 and WCRF 2014/1197).

\section{Disclosure}

All authors declare that they have no conflicts of interest.

\section{References}

1. Siegel RL, Miller KD, Fuchs HE, Jemal A. Cancer statistics, 2021. CA Cancer J Clin. 2021;71(1):7-33. doi:10.3322/caac.21654

2. Bodai BI, Tuso P. Breast cancer survivorship: a comprehensive review of long-term medical issues and lifestyle recommendations. Perm J. 2015;19(2):48-79. doi:10.7812/TPP/14-241

3. Molina-Montes E, Requena M, Sanchez-Cantalejo E, et al. Risk of second cancers cancer after a first primary breast cancer: a systematic review and meta-analysis. Gynecol Oncol. 2015;136 (1):158-171. doi:10.1016/j.ygyno.2014.10.029

4. Travis LB, Rabkin CS, Brown LM, et al. Cancer survivorship-genetic susceptibility and second primary cancers: research strategies and recommendations. $J$ Natl Cancer Inst. 2006;98(1):15-25. doi:10.1093/jnci/djj001

5. Sanchez L, Lana A, Hidalgo A, et al. Risk factors for second primary tumours in breast cancer survivors. Eur J Cancer Prev. 2008;17 (5):406-413. doi:10.1097/CEJ.0b013e3282f75ee5

6. Youlden DR, Cramb SM, Yip CH, Baade PD. Incidence and mortality of female breast cancer in the Asia-Pacific region. Cancer Biol Med. 2014;11(2):101-115. doi:10.7497/j.issn.2095-3941.2014.02.005

7. Overview of Hong Kong Cancer Statistics of 2018. Hong Kong Cancer Registry, Hospital Authority. Available from: http://www3.ha. org.hk/cancereg/. Accessed May 19, 2021.

8. Dianatinasab M, Mohammadianpanah M, Daneshi N, Zare-Bandamiri M, Rezaeianzadeh A, Fararouei M. Socioeconomic factors, health behavior, and late-stage diagnosis of breast cancer: considering the impact of delay in diagnosis. Clin Breast Cancer. 2018;18(3):239-245. doi:10.1016/j.clbc.2017.09.005

9. Lin $\mathrm{CH}$, Yap YS, Lee $\mathrm{KH}$, et al. Contrasting epidemiology and clinicopathology of female breast cancer in Asians vs the US Population. $\quad J$ Natl Cancer Inst. 2019;111(12):1298-1306. doi:10.1093/jnci/djz090
10. Accordino MK, Neugut AI, Hershman DL. Cardiac effects of anticancer therapy in the elderly. J Clin Oncol. 2014;32(24):2654-2661. doi:10.1200/JCO.2013.55.0459

11. Hu FB, Rimm E, Smith-Warner SA, et al. Reproducibility and validity of dietary patterns assessed with a food-frequency questionnaire. Am J Clin Nutr. 1999;69(2):243-249. doi:10.1093/ajcn/69.2.243

12. Hu FB. Dietary pattern analysis: a new direction in nutritional epidemiology. Curr Opin Lipidol. 2002;13(1):3-9. doi:10.1097/ 00041433-200202000-00002

13. Hou R, Wei J, Hu Y, et al. Healthy dietary patterns and risk and survival of breast cancer: a meta-analysis of cohort studies. Cancer Causes Control. 2019;30(8):835-846. doi:10.1007/s10552-01901193-Z

14. Xiao Y, Xia J, Li L, et al. Associations between dietary patterns and the risk of breast cancer: a systematic review and meta-analysis of observational studies. Breast Cancer Res. 2019;21(1):16. doi:10.1186/s13058-019-1096-1

15. Zhang L, Huang S, Cao L, Ge M, Li Y, Shao J. Vegetable-fruitsoybean dietary pattern and breast cancer: a meta-analysis of observational studies. J Nutr Sci Vitaminol (Tokyo). 2019;65(5):375-382. doi:10.3177/jnsv.65.375

16. Dianatinasab M, Rezaian M, HaghighatNezad E, et al. Dietary patterns and risk of invasive ductal and lobular breast carcinomas: a systematic review and meta-analysis. Clin Breast Cancer. 2020;20 (4):e516-e528. doi:10.1016/j.clbc.2020.03.007

17. Kroenke CH, Fung TT, Hu FB, Holmes MD. Dietary patterns and survival after breast cancer diagnosis. J Clin Oncol. 2005;23 (36):9295-9303. doi:10.1200/JCO.2005.02.0198

18. Kwan ML, Weltzien E, Kushi LH, Castillo A, Slattery ML, Caan BJ. Dietary patterns and breast cancer recurrence and survival among women with early-stage breast cancer. J Clin Oncol. 2008;27 (6):919-926. doi:10.1200/JCO.2008.19.4035

19. Vrieling A, Buck K, Seibold P, et al. Dietary patterns and survival in German postmenopausal breast cancer survivors. $\mathrm{Br} J$ Cancer. 2013;108(1):188-192. doi:10.1038/bjc.2012.521

20. Wang F, Cai H, Gu K, et al. Adherence to dietary recommendations among long-term breast cancer survivors and cancer outcome associations. Cancer Epidemiol Biomarkers Prev. 2020;29 (2):386-395. doi:10.1158/1055-9965.EPI-19-0872

21. Lei YY, Ho SC, Cheng A, et al. Dietary changes in the first 3 years after breast cancer diagnosis: a prospective Chinese breast cancer cohort study. Cancer Manag Res. 2018;10:4073-4084. doi:10.2147/ CMAR.S168562

22. Lei YY, Ho SC, Cheng A, et al. Adherence to the world cancer research fund/American Institute for cancer research guideline is associated with better health-related quality of life among Chinese patients with breast cancer. J Natl Compr Canc Netw. 2018;16 (3):275-285. doi:10.6004/jncen.2017.7202

23. Lei YY, Ho SC, Cheng A, et al. The association between soy isoflavone intake and menopausal symptoms after breast cancer diagnosis: a prospective longitudinal cohort study on Chinese breast cancer patients. Breast Cancer Res Treat. 2020;181(1):167-180. doi:10.1007/s10549-020-05616-3

24. Edge SBBD, Compton CC, Fritz AG, Greene FL, Trotti A, editors. AJCC Cancer Staging Manual. 7th ed. New York, NY: Springer; 2010.

25. Ho SC, Yu R, Chan S. Comparison of the modified Chinese Baecke Questionnaire with a 3-day activity diary in a Hong Kong Chinese population. Asia Pac J Public Health. 2015;27(2):Np2358-2371. doi:10.1177/1010539511416805

26. WHO/IASO/IOTF. The Asia-Pacific perspective: redefining obesity and its treatment. Melbourne, Australia: Health Communications Australia; 2000.

27. Zhang CX, Ho SC. Validity and reproducibility of a food frequency Questionnaire among Chinese women in Guangdong province. Asia Pac J Clin Nutr. 2009;18(2):240-250. 
28. Yang. Y-X, Wang. G-Y, Pan. X-C. China Food Composition 2002. Beijing, China: Peking University Medical Press; 2002.

29. Kim J-O, Mueller CW. Factor analysis: statistical methods and practical issues. Beverly Hills, Calif: Sage Publications; 1978.

30. Schoenfeld D. Partial residuals for the proportional hazards regression model. Biometrika. 1982;69(1):239-241. doi:10.1093/biomet/ 69.1.239

31. George SM, Irwin ML, Smith AW, et al. Postdiagnosis diet quality, the combination of diet quality and recreational physical activity, and prognosis after early-stage breast cancer. Cancer Causes Control. 2011;22(4):589-598. doi:10.1007/s10552-011-9732-9

32. George SM, Ballard-Barbash R, Shikany JM, et al. Better postdiagnosis diet quality is associated with reduced risk of death among postmenopausal women with invasive breast cancer in the women's health initiative. Cancer Epidemiol Biomarkers Prev. 2014;23 (4):575-583. doi:10.1158/1055-9965.EPI-13-1162

33. Chlebowski RT, Blackburn GL, Thomson CA, et al. Dietary fat reduction and breast cancer outcome: interim efficacy results from the Women's Intervention Nutrition Study. J Natl Cancer Inst. 2006;98(24):1767-1776. doi:10.1093/jnci/djj494

34. Pierce JP, Natarajan L, Caan BJ, et al. Influence of a diet very high in vegetables, fruit, and fiber and low in fat on prognosis following treatment for breast cancer: the Women's Healthy Eating and Living (WHEL) randomized trial. JAMA. 2007;298(3):289-298. doi:10.1001/jama.298.3.289
35. Esmaillzadeh A, Kimiagar M, Mehrabi Y, Azadbakht L, Hu FB, Willett WC. Dietary patterns and markers of systemic inflammation among Iranian women. $J$ Nutr. 2007;137(4):992-998. doi:10.1093/jn/ 137.4.992

36. Labonte ME, Couture P, Richard C, Desroches S, Lamarche B. Impact of dairy products on biomarkers of inflammation: a systematic review of randomized controlled nutritional intervention studies in overweight and obese adults. Am J Clin Nutr. 2013;97 (4):706-717. doi:10.3945/ajcn.112.052217

37. Ma Y, Hebert JR, Li W, et al. Association between dietary fiber and markers of systemic inflammation in the Women's Health Initiative Observational Study. Nutrition. 2008;24(10):941-949. doi:10.1016/j. nut.2008.04.005

38. Hsieh CC, Wang CH. Aspirin disrupts the crosstalk of angiogenic and inflammatory cytokines between $4 \mathrm{~T} 1$ breast cancer cells and macrophages. Mediators Inflamm. 2018;2018:6380643. doi:10.1155/ 2018/6380643

39. Runowicz CD, Leach CR, Henry NL, et al. American Cancer Society/American Society of Clinical Oncology Breast Cancer Survivorship Care Guideline. J Clin Oncol. 2016;34(6):611-635. doi:10.1200/JCO.2015.64.3809

40. Martinez ME, Marshall JR, Sechrest L. Invited commentary: factor analysis and the search for objectivity. Am J Epidemiol. 1998;148 (1):17-19. doi:10.1093/oxfordjournals.aje.a009552

\section{Publish your work in this journal}

Cancer Management and Research is an international, peer-reviewed open access journal focusing on cancer research and the optimal use of preventative and integrated treatment interventions to achieve improved outcomes, enhanced survival and quality of life for the cancer patient.
The manuscript management system is completely online and includes a very quick and fair peer-review system, which is all easy to use. Visit http://www.dovepress.com/testimonials.php to read real quotes from published authors. 